\section{Congenital corneal opacities - a surgical approach to nomenclature and classification}

\begin{abstract}
The classification system of congenital corneal opacification (CCO) may be better considered from a perspective of pathogenesis, surgical intervention, and prognosis. The author feels that $\mathrm{CCO}$ is best considered as being primary and secondary. Primary CCO includes corneal dystrophies and choristomas presenting at birth. Secondary CCO may be best considered as cases of kerato-irido-lenticular dysgenesis (KILD) and other secondary causes including infection, iatrogenic, developmental anomalies of the iridotrabecular system or lens or both, and developmental anomalies of the adnexal. The appropriate classification may help determine prognosis of any surgical intervention. Terminology is crucial to furthering our understanding of the formation of the anterior chamber if we are to do so by studying cases of CCO. Peters' anomaly is too imprecise a term to describe cases of CCO. This classification of primary and secondary CCO with its subclassifications cannot be made by clinical examination alone and necessitates other diagnostic assessments. It is time to only accept studies of CCO genotype/ phenotype correlation for publication if there is clinical phenotype augmented by anterior segment imaging (OCT or high-frequency ultrasound) or histology or both.
\end{abstract}

Eye (2007) 21, 1326-1337; doi:10.1038/sj.eye.6702840

KK Nischal, Department of Clinical and Academic Ophthalmology, Great Ormond St Hospital for Children Ulverscroft Vision Research Group, Institute of Child Health, London, UK Tel: 0207813 8524;

Fax: 02078298647 .

E-mail:kkn@

btinternet.com
KK Nischal

Infectious - Most commonly Herpes simplex

keratitis in the developed world

Dystrophic - Congenital hereditary endothelial dystrophy (CHED) or posterior polymorphous dystrophy (PPMD)

Iatrogenic - Amniocentesis injury or forceps delivery injury

Developmental - Traditionally described as Peters' anomaly or sclerocornea

Metabolic disorders rarely cause clinically significant corneal opacification at birth or within 4 weeks of birth.

Although such a classification may be helpful to remember all the aetiologies involved, it is unhelpful to help understand possible pathogenesis or which cases of CCO are likely to do well with surgical intervention, namely penetrating keratoplasty.

This is an important concept and a departure from traditional rationalization. Traditional need not mean old in this context, because even very recent articles ${ }^{1}$ concerning this subject have perpetuated a classification system which does not lend itself to application for useful assessment of surgical or management outcomes. Formation of the anterior chamber and therefore by implication, the cornea, is a complex developmental process that involves the lens, head ectoderm, neuroectoderm, primitive mesoderm, and neural crest cells. As will unfold in this article, terminology is crucial to furthering our understanding of this complex subject.

Describing a developmental corneal opacity as being Peters' anomaly is akin to diagnosing someone with a respiratory problem as having a cough. It is neither precise, diagnostic, nor informative about prognosis.

Peters $^{2}$ described a condition affecting the cornea approximately 100 years ago when high-frequency ultrasound (HFU) and ocular coherence tomography (anterior segment) were 
not available. The advent of these has helped define phenotype much more precisely. ${ }^{3}$

It is with this added knowledge that it may be more rational to consider $\mathrm{CCO}$ as being primary or secondary with a separate category of kerato-irido-lenticular dysgenesis (KILD).

\section{Primary $C C O-P C C O)$}

a. Developmental anomalies of cornea only

i. Corneal dystrophies

1. Congenital hereditary endothial dystrophy (CHED) see Figure 2

2. Posterior polymorphous dystrophy (PPMD) see Figure 1

ii. Corneal structural defects due to dermoids

1. Peripheral due to limbal dermoid

2. Central corneal dermoid

iii. Isolated sclerocornea (without microphthalmos and with normal anterior chamber)

2. Secondary CCO - (KILD)

a. Lens fails to separate from cornea

i. Developmental

a. As seen in Dyl mouse ${ }^{17}$

ii. Mechanical : clues to this include

1. Lens epithelium discernible, for example, see Figure 10

2. Evidence of persistent pupillary type membrane(s)

3. Intact iris stromal architecture, for example, see Figure 13

b. Lens separates but fails to form thereafter, for example, see Figure 7

c. Lens fails to form

i. As seen in aph mouse ${ }^{27}$

d. Due to PHPV

3. Secondary CCO - Others

a. Infectious

b. Iatrogenic

c. Developmental anomalies of iridotrabecular system or lens or both

i. Infantile congenital glaucoma

ii. Aniridia

iii. Axenfeld-Rieger anomaly/syndrome

iv. Associated with persistent hyperplastic primary vitreous (PHPV)

v. Whole globe abnormality (includes complex microphthalmos)

vi. Corneal ectasia

d. Developmental anomalies of the adnexa

i. Clefting syndromes

\section{Primary congenital corneal opacification}

\section{Developmental anomalies of the cornea only}

Congenital hereditary endothelial dystrophy/posterior polymorphous dystrophy (CHED/PPMD)

Developmental anomalies of the cornea alone include CHED and PPMD. Both can coexist with glaucoma. ${ }^{4,5}$

CHED always occurs at birth, whereas PPMD may occur at birth (Figure 1). Type 1 CHED (CHED I) tends to be autosomal dominant and less severe, whereas type 2 tends to be autosomal recessive and more severe ${ }^{6}$ (Figure 2). Both
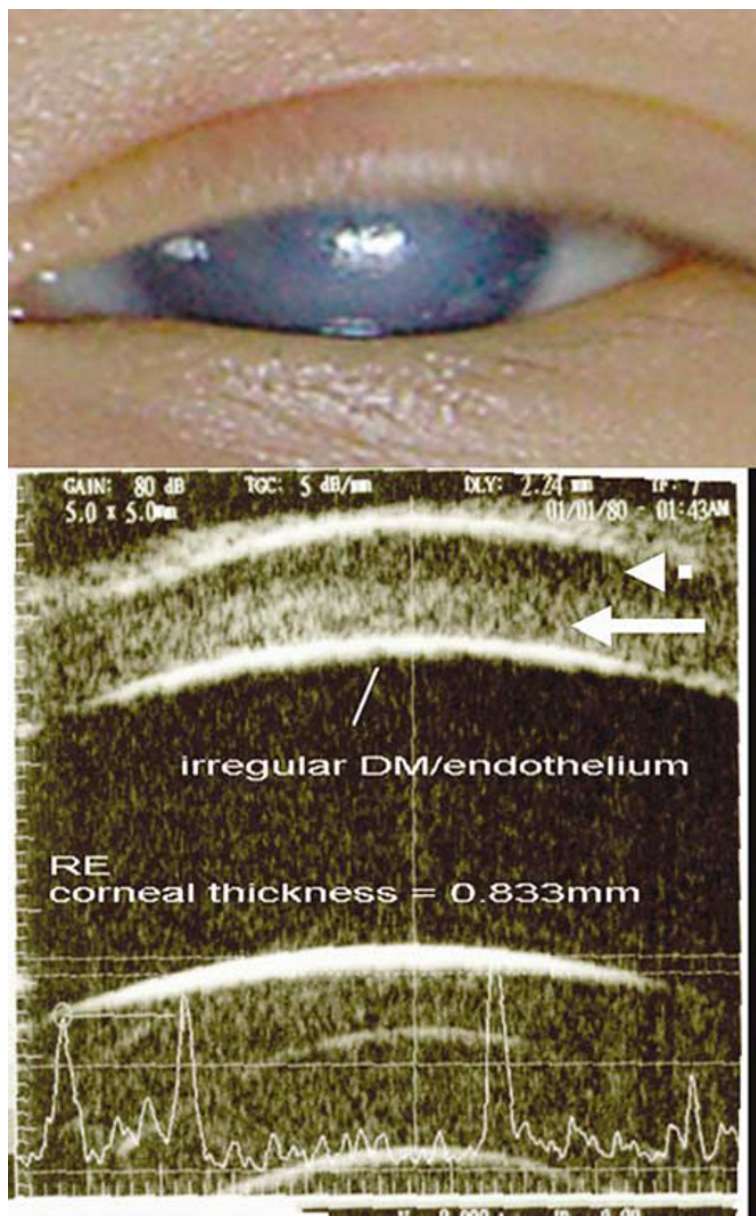

Figure 1 A child with PPMD presenting at birth. Glaucoma had been excluded. The HFU shows a thickened cornea $(833 \mu \mathrm{m})$ with evidence of oedema in the posterior stroma with evidence of irregular endothelial/Descemet's complex. The maternal uncle was examined owing to a history of similar corneal haze and was found to have typical corneal changes of PPMD.

PPMD and CHED I have been localized to chromosome $20,{ }^{6}$ and it is suggested that they may be allelic. ${ }^{7}$ CHED II has been associated with mutations in SLC4A11. ${ }^{8}$

Some authors consider these conditions to be neurocristopathies, ${ }^{9}$ resulting from a failure of regression of the primordial endothelium during development of the anterior chamber; the degree of failure of regression corresponds to the clinical condition, with marked failure resulting in CHED and less or little failure resulting in PPMD. The suggestion then is that primary congenital glaucoma is also a neurocristopathy, ${ }^{9}$ again resulting due to a sheet of primordial endothelium failing to fenestrate appropriately within the angle and causing the iris to insert high and flat (Figure 3). This tissue almost causes the iris root to 'hang up', with goniotomy allowing release of the iris root and exposing trabecular meshwork. Although somewhat speculative, this does provide a plausible explanation for these conditions. 
In terms of surgical intervention there are reports of reasonable to good surgical success in cases of CHED and PPMD. ${ }^{10}$

For a primary developmental congenital corneal opacity this should not be surprising.

\section{Corneal structural defects}

\section{Dermoids}

These are choristomas of the cornea. The most common type is limbal and may be associated with the auriculo-oculo-vertebral syndrome (Goldenhar). ${ }^{11}$ Occasionally these dermoids may be extensive and may even invade the anterior chamber. ${ }^{12}$ Generally speaking, limbal dermoids may be removed by shaving or by performing lamellar keratoplasty. ${ }^{13}$ Published literature suggests that the degree of astigmatism in both methods is the same. ${ }^{13}$ Deeper more extensive corneal dermoids necessitate penetrating keratoplasty. The prognosis as long as the anterior chamber is not disrupted by the lesion, is reasonably good. ${ }^{13}$

\section{Isolated sclerocornea}

This is another condition the nature of which, in my mind, has been muddied by traditional nomenclature. It is better considered as isolated, complex, or total.

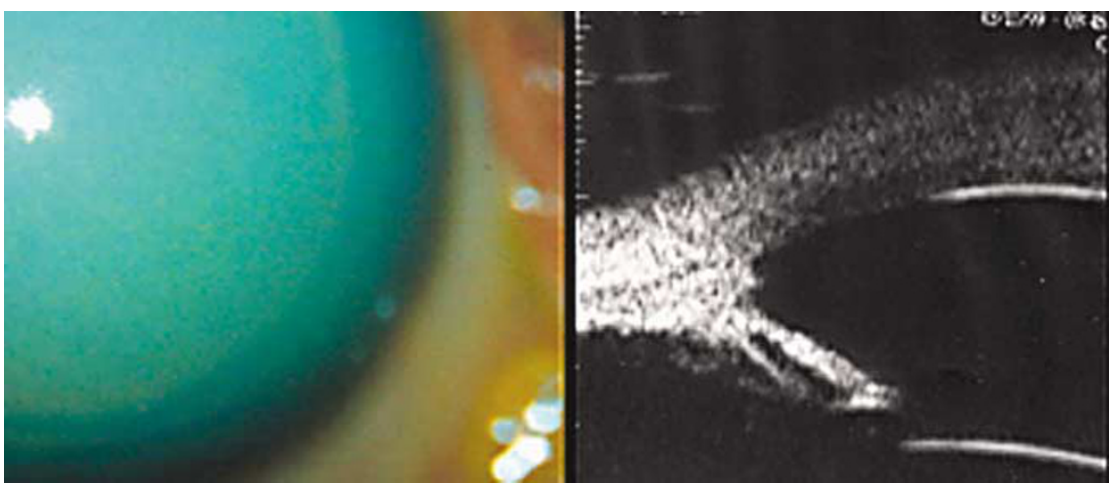

Figure 2 CHED type 2. Note the marked CCO and corneal thickening on HFU but with a normal anterior segment otherwise (courtesy of Leslie MacKeen).

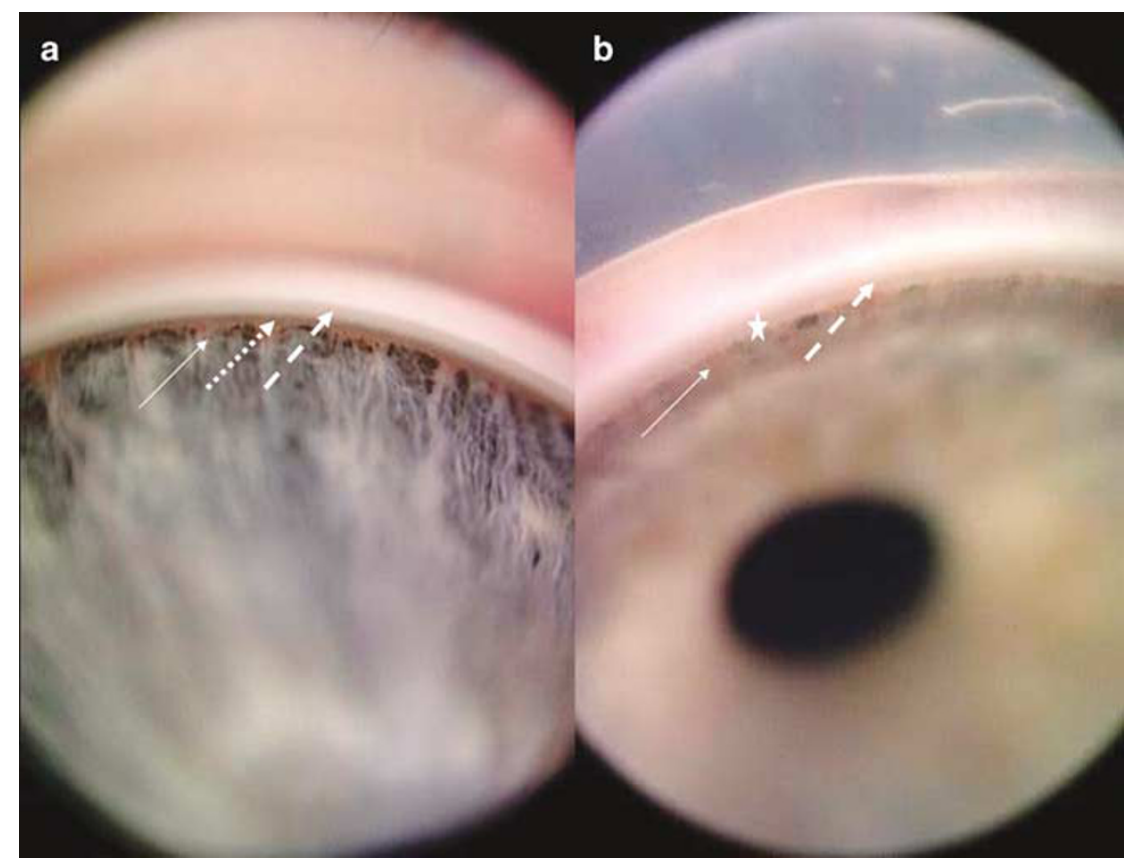

Figure 3 (a) Normal 4 months old. Iris root (white arrow), ciliary body band (dotted white arrow), trabecular meshwork (dashed white arrow). Note there is no easily discernible scleral spur. (b) 7 months old with glaucoma. Dashed and solid white arrows as above. The ciliary body band is not visible. There is an amorphous type material obscuring the trabecular meshwork partially (white star). Note the high insertion of the iris root with a peripheral concavity evidenced by the defocus of that area (courtesy of Leslie MacKeen). 
Isolated sclerocornea is due to an anterior displacement of the limbal arcades and may be associated with cornea plana ${ }^{14,15}$ (corneal power $<38 \mathrm{D}$ ). Some authors prefer to term this sclerocornea plana but this author feels this is confusing. In isolated sclerocornea (Figure 4), the anterior chamber is visible and the eye is not microphthalmic. The anterior chamber depth may be slightly shallow. As the child grows secondary glaucoma may develop but infantile glaucoma is not present.

In complex sclerocornea, there may be associated microphthalmos, cataract, infantile glaucoma, or any combination of these ${ }^{16}$ (Figure 5). There is usually always a relative central clearing but the thickness of this relatively clear area is normal or increased, never reduced (see Figure 6). This condition is better

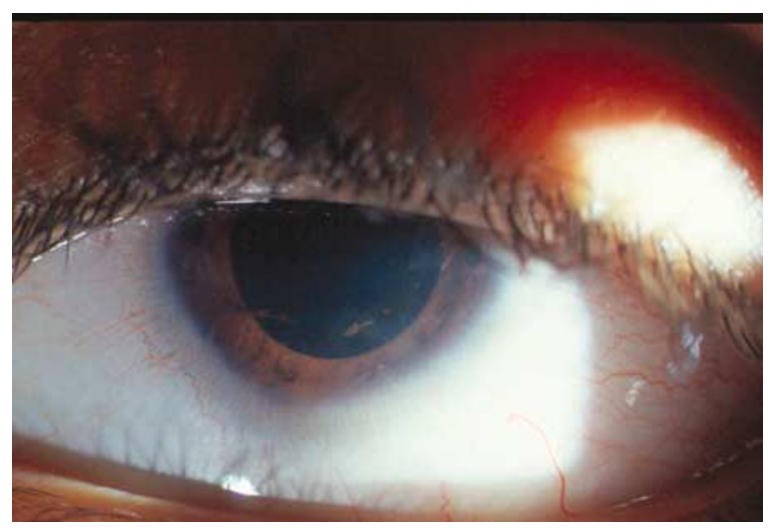

Figure 4 Isolated sclerocornea with cornea plana. This is a primary $\mathrm{CCO}$ as the lens and iris are normal.

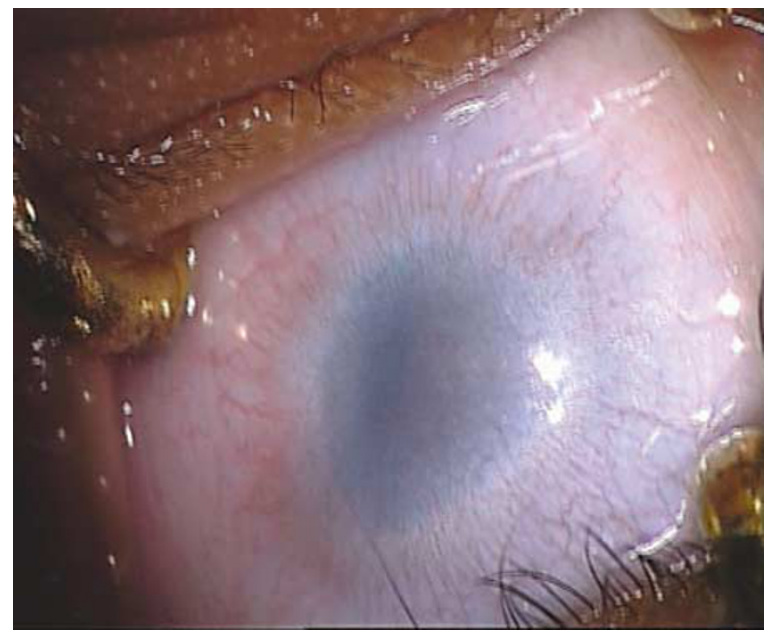

Figure 5 Secondary CCO (severe sclerocornea) with cataract, coloboma, and microphthalmos. The child was small for age, had failure to thrive with cardiac anomalies also. Chromosomal analysis was normal. considered as part of 'a whole globe' abnormality from the point of genetic evaluation.

Total sclerocornea may be better classified in some cases as a form of keratolenticular dysgenesis, ${ }^{3}$ due to lens/iris disruption (Figure 7 ) or failure of lens to separate from the cornea.

Displacement of the limbal arcades anteriorly may occur asymmetrically (Figure 8 ) and if this is excised to reveal the true extent of the cornea (Figure 8), this results in scarring in that area of the donor graft presumably because the limbal stem cell architecture has been disrupted.

\section{Secondary CCO - kerato-irido-lenticular dysgenesis (KILD)}

\section{Lens fails to separate from the cornea}

\section{Developmental}

Sanyal and Hawkins ${ }^{17}$ have described a mutant mouse model called dysgenetic lens mouse or the dyl mouse, the ocular features of which are failure of lens-ectoderm separation. Additionally lack of a proliferating anterior lens epithelium leads to absence of secondary lens fibres and a dysplastic, cataractous lens. In 2000, the gene responsible for this in the mouse was recognized as FoxE3. ${ }^{18}$ This gene encodes a forkhead/winged helix transcription factor, which is expressed in the developing lens at the start of lens placode induction and becomes restricted to the anterior proliferating cells when lens fibre differentiation begins.

Mutations in FOXE3, the human analogue, have been described in one individual (of 13 investigated) with a diagnosis of Peters' anomaly. ${ }^{19}$ Although this is

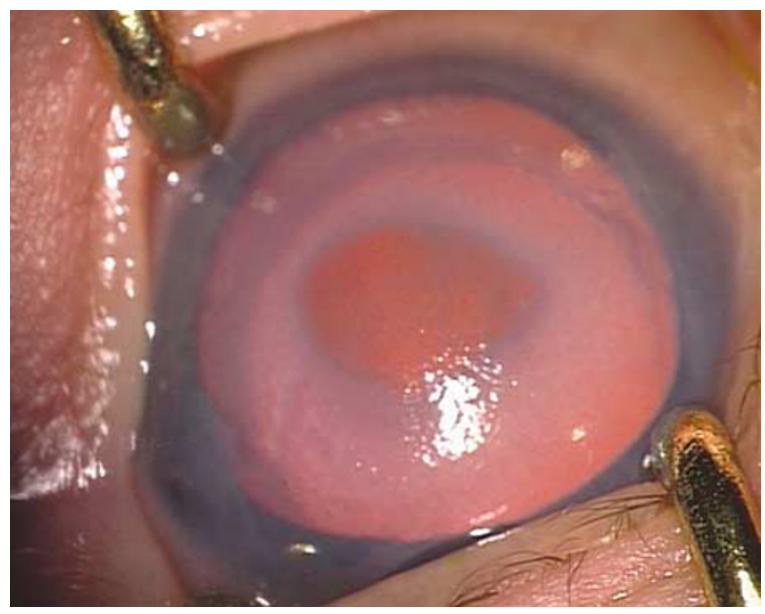

Figure 6 The relative central clarity in this case is due to marked thinning of the cornea . This is not sclerocornea. Note there is no corneal vascularization. 


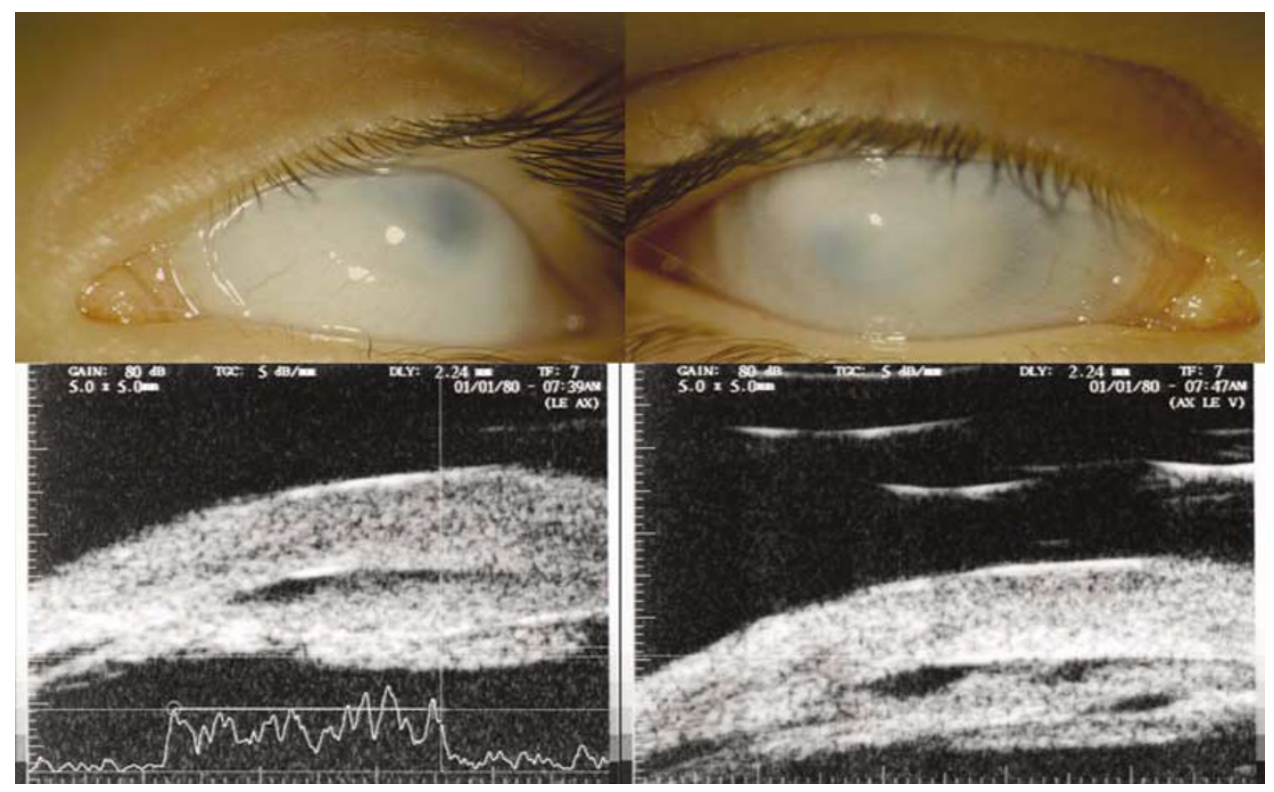

Figure $7 \mathrm{CCO}$ with disruption of the lens and iris. Traditionally this would be classed as sclerocornea but the disruption of the anterior segment warrants another classification. Keratolenticular dysgenesis is proposed whereby the lens vesicle separates but then fails to form appropriately. See text.

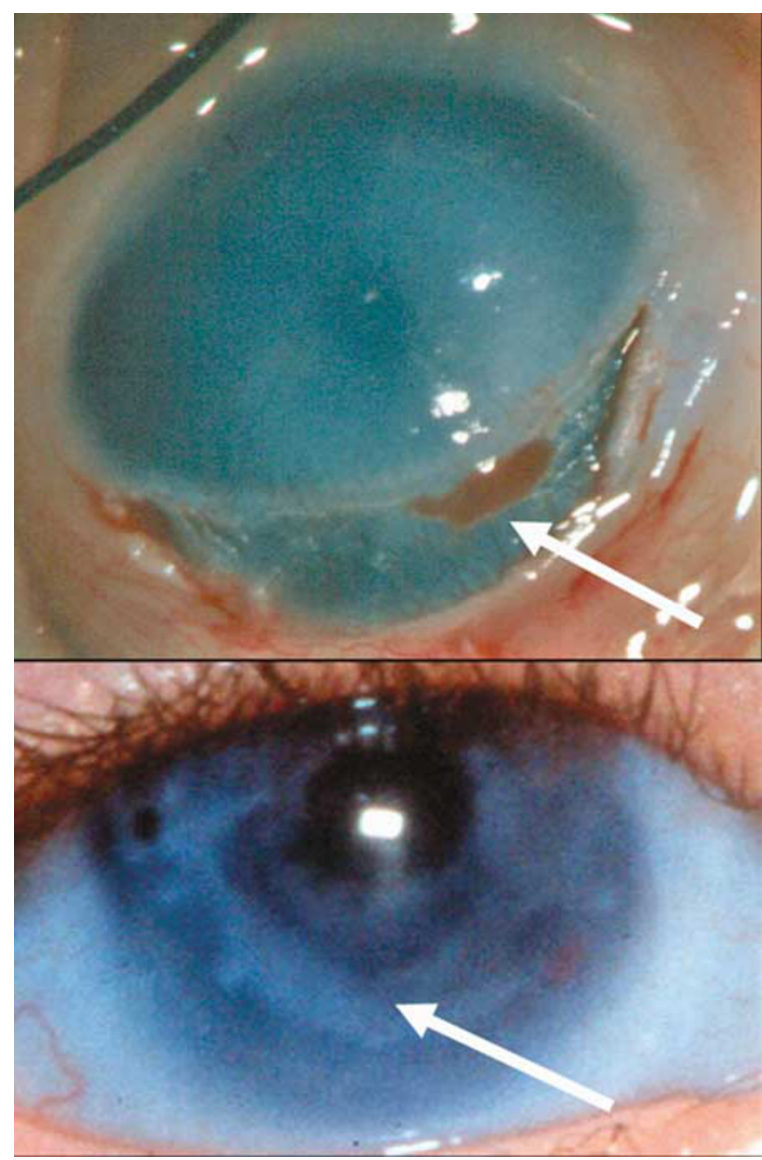

obviously an important finding, the fact that only one case was found to have the mutation in FOXE3 is hardly surprising because the phenotype is described as Peters' anomaly. This is too imprecise. For example, see Figure 9 showing disruption of the lens with kerato-irido-lenticular dysgenesis (KILD). There is no anterior capsule echo discernible. Compare this to Figure 10 where there clearly is. On the basis of HFU and clinical appearance it is much more likely that the case in Figure 9 would have a FOXE3 mutation rather than the case in Figure 10. Both cases may be termed as having Peters' anomaly.

Other mouse gene mutations, for example, in Cat $4^{a}$ have also been described to cause failure of lens ectoderm separation in the heterozygous state and microphthalmia in the homozygous state. ${ }^{20} \mathrm{In}$ animal models, acute embryonic insults during gastrulation have also resulted in kerato-lenticular adhesions. ${ }^{21}$

Figure 8 A case of $\mathrm{CCO}$ with iridocorneal adhesion and mild posterior corneal defect. However, there is clearly anterior displacement of the limbus as might be seen in sclerocornea. This displacement is asymmetric and peritomy reveals the true extent of the corneal tissue. This eye had PKP and 4 years later one can see scarring in the area of limbal peritomy and tissue excision; presumably due to limbal stem cell disruption. 


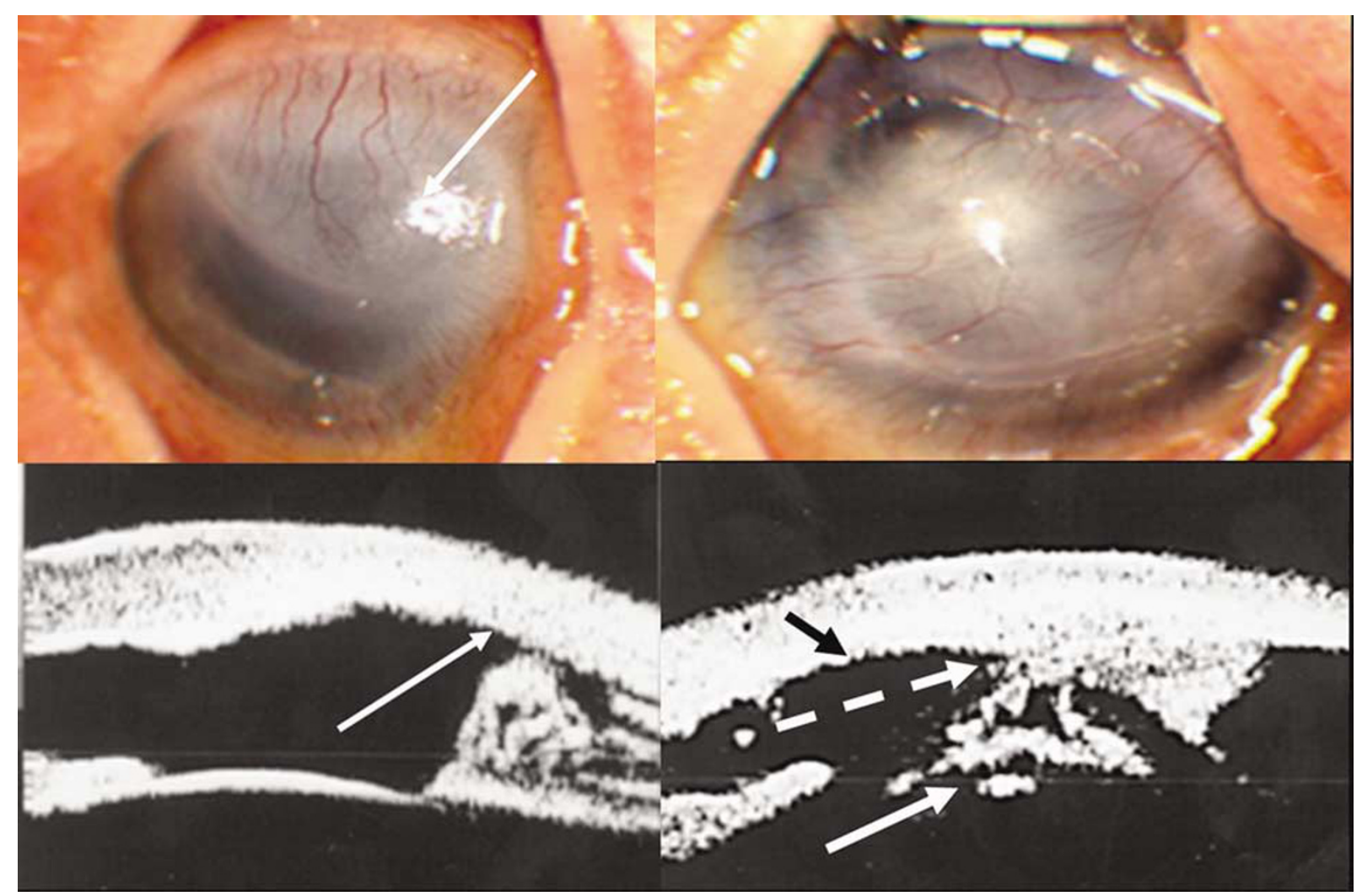

Figure $9 \mathrm{CCO}$ due to KILD. On the left there is vascularization of the cornea with opacification which corresponds to the area of posterior corneal defect and iridocorneal adhesion with abnormal iris stroma (white arrows) on the HFU. Compare this to Figure 13. On the right side there is clear keratolenticular dysgenesis with disruption of the lens (white arrow) and anterior capsule (dashed arrow) and a posterior corneal defect (black arrow). Compare this to Figures 7 and 9 (courtesy of Dr Kranjc).

\section{Mechanical}

This is suggested because although many developmental CCOs may be due to a mishap of genetic orchestration, some are $\operatorname{not}^{22}$ and may be due to a mechanical or physical touch of cornea and lens. This has been well recognized for sometime, ${ }^{22}$ but is repeatedly neglected in the nonsurgical literature. ${ }^{1}$

During development the anterior segment volume is so small that the whole fetal anterior chamber would fit into the normal adult pupillary diameter. ${ }^{23}$ This anterior segment fetal area is occupied by a well-defined vascular membrane which eventually involutes. It is feasible that hypoxia and other insults may cause increased vascular permeability, transudation, and adhesion of this membrane to the cornea resulting in damage to Descemet's membrane and corneal endothelium. ${ }^{22}$ The case in Figure 11A may be explained in this manner.

Similarly, there are cases of keratolenticular adhesion which are due to a physical delay in separation with an

Figure $10 \mathrm{CCO}$ due to an isolated keratolenticular adhesion. Note the CCO is avascular and the iris and lens structure otherwise normal.

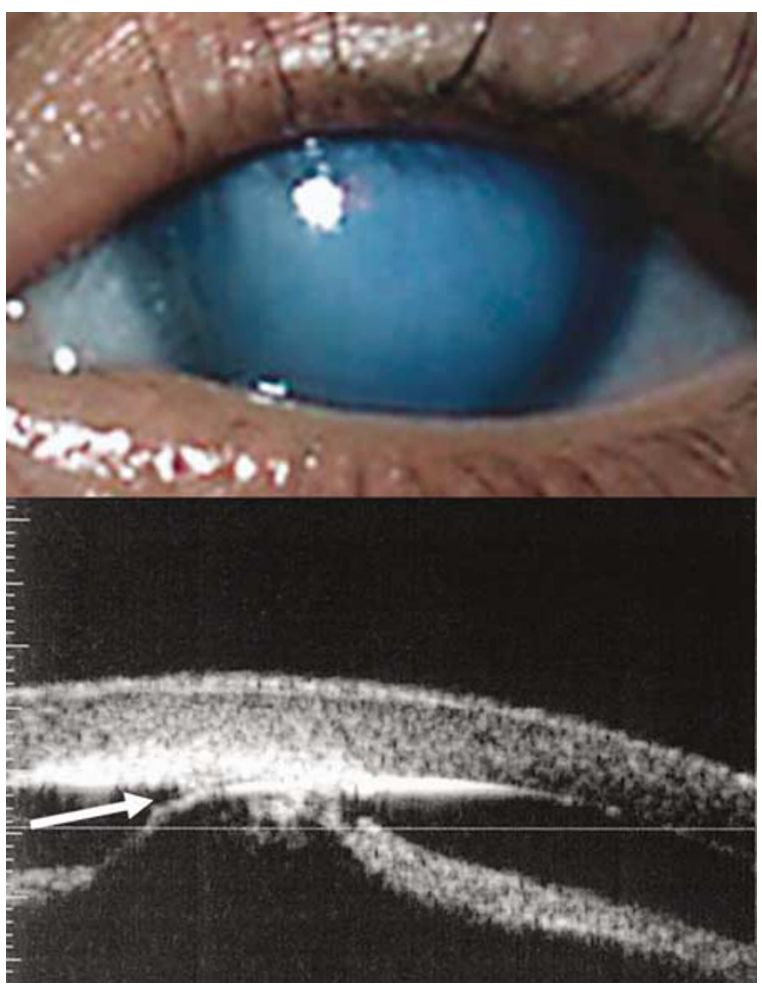


essentially normal lens and normal cornea otherwise as seen in the case in Figure 11B. This shows the mildest end of the spectrum of keratolenticular adhesion with iridocorneal adhesion. In a unilateral and otherwise healthy eye, it is difficult to explain this from a genetic developmental point.

The characteristic feature of such mechanical touches is a lack of corneal vascularization (Figures 10, 12 and 13). Again the distinction is important because synechiolysis or peeling off the keratolenticular adhesion with heavy viscoelastic may result in a focal discrete lens opacity and corneal scar. The prognosis for penetrating keratoplasty in such cases is reduced only if there is exposure of the vitreous to the donor endothelium; in other words, if a vitreo-lensectomy needs to be performed at the time of penetrating keratoplasty. Once again this differentiation is helpful for prognosis of intervention with penetrating keratoplasty (PKP) (see Figure 14).

\section{Lens separates but fails to form thereafter}

Lens/iris disruption (cause as yet undefined)

Figure 7 shows a case of a child diagnosed elsewhere as having sclerocornea. The HFU evaluation shows disruption of the lens and iris, suggesting that this is likely to be failure of the lens to form properly although it appears from the HFU that it has separated from the cornea. Classic transplantation studies have implicated the anterior surface of the lens as the source of diffusible factors important in differentiation of cornea and iris. ${ }^{24,25}$

PITX3 has been implicated as a gene, mutations in which may result in a condition called anterior segment mesenchymal dysgenesis (ASMD), which can include severe CCO. ${ }^{26}$ Whether PITX3 has a role in certain phenotypes of developmental CCO due to KILD remains to be investigated further.

\section{Lens fails to form}

\section{Primary aphakia}

In the mouse model ak (aphakia mouse) mutations in pitX3 have been shown to be responsible for this phenotype, ${ }^{27}$ whereas recently, in humans homozygous nonsense mutations in FOXE3 have been implicated in congenital primary aphakia. ${ }^{28}$

In humans it is an extremely rare condition; ${ }^{29,28}$ it is not the same as a resorbed lens (as might be seen in Hallermann-Streiff syndrome). In primary aphakia the lens has not formed at all and as a result the anterior segment architecture is extremely abnormal.

The cornea in these cases seems to have a typical appearance of a silver/blue colour (Figure 15). At surgery the cornea appears to have little or no stroma.
Embryologically this makes sense because the lens vesicle induces basal ectodermal cells to form a multilayered structure, the cells of which increase in size and secrete the primary stroma. If there is no lens vesicle, then there is likely to be no primary stroma.

This diagnosis is very important because to date almost all such cases operated upon result in an unusual cicatricial membrane that causes phthisis.

\section{Persistent hyperplastic primary vitreous}

CCO has been described in association with Persistent hyperplastic primary vitreous (PHPV). ${ }^{30}$ In fact a mouse model has also been produced of this phenotype. ${ }^{31}$ Whether the pathogenesis is due to a mechanical pushing forward of the lens or not, is at present unclear.

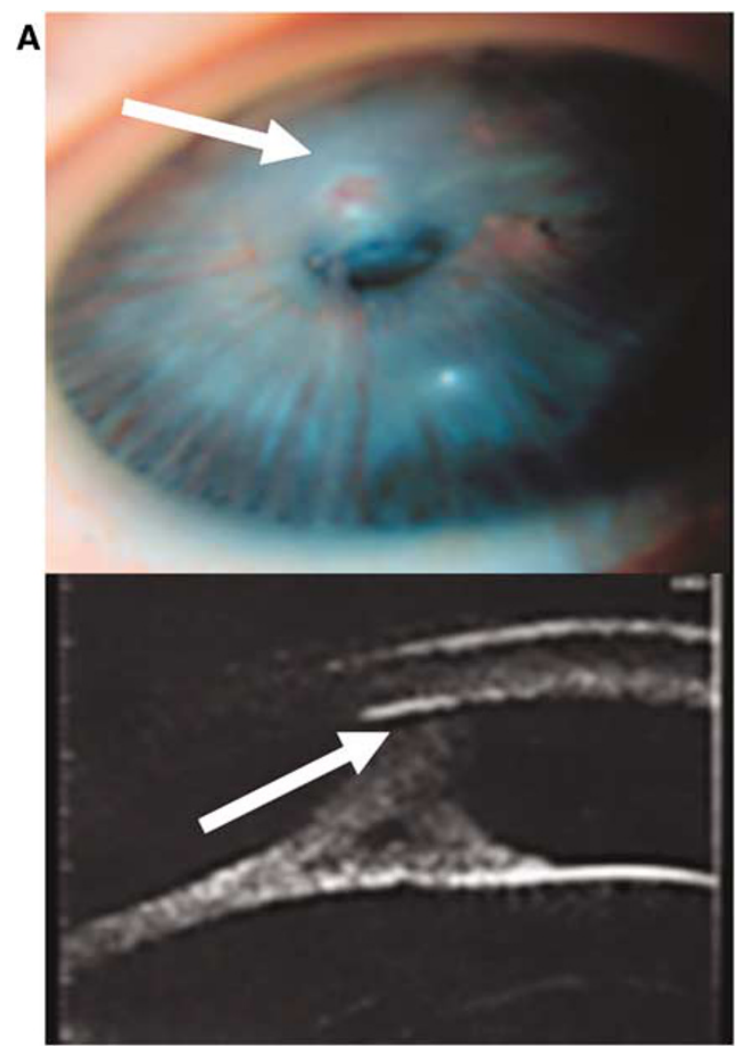

Figure 11 (A) Iridocorneal adhesions without iris stromal structural anomaly. The vascularization seen in the clinical picture is within the iris and likely due to persistent pupillary membranes and not the cornea. The CCO is avascular. (B) A very mild case of CCO. There is a keratolenticular adhesion (white arrow) ( $a$ and $b$ seen with RetCam; courtesy of Leslie MacKeen), which causes a discrete CCO clinically and is seen on HFU (c). Note there is minimal if any corneal defect seen on the ultrasound scan. (d) The dashed white arrow shows an iridocorneal adhesion. Note the lens and iris are otherwise normal in structure. This again is more likely to be due to a mechanical touch. 
B

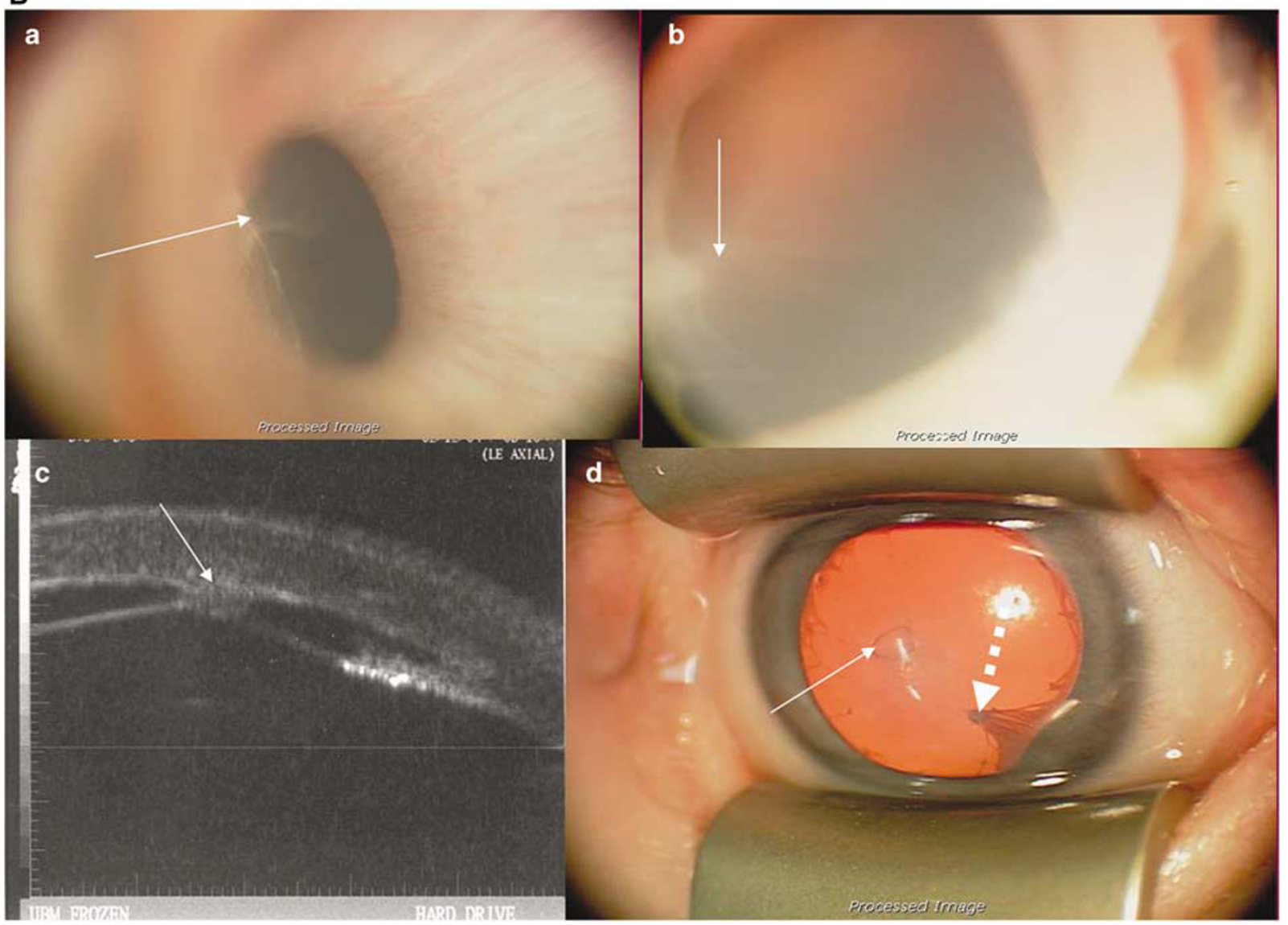

Figure 11 Continued

\section{Secondary congenital corneal opacification - other}

\section{Infectious}

Herpes simplex keratitis may present at birth (Figure 16). Although it has been thought that the infection is acquired during passage through the birth canal, cases have been described where the mother has found to be negative on microbiological evaluation. ${ }^{32}$ Both HSV type 1 and 2 have been implicated. The prognosis may be poor mainly because of the amblyopic effect in the first few weeks of life. The infant often needs an examination under anaesthetic for corneal valuation corneal scrapes. The infant needs a full paediatric review as the ocular condition may be the only manifestation of a systemic infection including hepatitis and early encephalitis. Systemic and topical acyclovir are often needed.

In the developing world, bacterial keratitis can occur soon after birth.

\section{Iatrogenic}

Amniocentesis injury ${ }^{33}$ can often be difficult to differentiate from a developmental $\mathrm{CCO}$ (either secondary or primary). The clue is often the very linear nature of the defect. Forceps injuries are easier to recognize with a history of a difficult labour and periorbital bruising and linear breaks in Descemet's membrane where the forceps blade inadvertently pressed on the cornea.

\section{Developmental anomalies of iridotrabecular system}

\section{Primary infantile glaucoma}

Most cases of primary infantile glaucoma are detected relatively early and although a child may present with corneal haze it is very unusual for a child to present late with neglected congenital glaucoma, unlike parts of the developing world where access to medical care means that children present with stromal corneal scarring secondary to longstanding corneal oedema. Under such circumstances penetrating keratoplasty is necessary to aid visual rehabilitation after adequate control of the glaucoma. The prognosis for corneal graft survival in such cases is directly dependent on the success of glaucoma control. 
Mutations in CYP1B1 are known to cause primary infantile glaucoma. ${ }^{34}$ If one considers for a moment that primary infantile glaucoma may be caused by a failure of fenestration of primordial endothelial cells, ${ }^{9}$ it would not be inconceivable that an extension of such abnormal primordial endothelium may cause the anterior surface

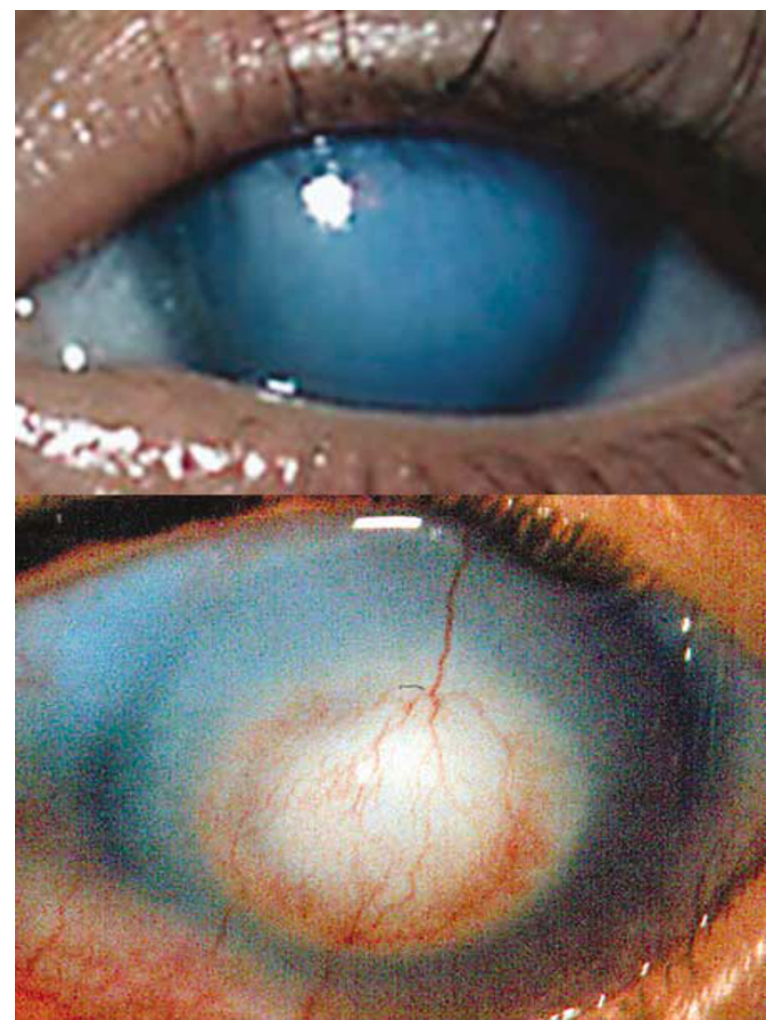

Figure 12 The picture above is the same as that from Figure 10 . The picture below is that of a child with bilateral CCO who has HFU proven aniridia (in the undilated state!) with glaucoma. This child is negative for PAX6 mutations known to cause aniridia. Note the vascularization of the central CCO with sparing of the peripheral cornea. of the iris to become adherent to the inner surface of the cornea resulting in a congenital CCO. Not surprisingly then, recently, mutations in CYP1B1 have been reported to cause 'Peters' anomaly' ${ }^{35,36}$ Whether one would categorize this type of $\mathrm{CCO}$ due to mutations in CYP1B1 gene as secondary due to primary infantile glaucoma or as part of the KILD category, needs further evaluation, but for the sake of brevity it is described here.

\section{Aniridia}

PAX6 mutations are known to cause aniridia and cases of Peters' anomaly have been described to have mutations in PAX6 also. ${ }^{37}$ Previously, we have shown that CCO may be associated with aniridia. ${ }^{3}$ Aniridia can also of course be associated with anterior polar or pyramidal cataracts which can cause keratolenticular adhesions with often discrete focal CCO. Whether the CCO seen with aniridia $^{38}$ is due to a mechanical fault or developmental is difficult to be certain about. ${ }^{22}$ The prognosis for PKP in cases associated with aniridia again is dependent on the need for vitreo-lensectomy at the time of PKP and the onset of glaucoma, both of which are poor prognosticators.

Once again reports of PAX6 not being responsible for 'Peters' anomaly' ${ }^{39}$ are confusing because the phenotype 'Peters' anomaly' is too imprecise: if a child with CCO has aniridia, anterior polar cataract, and nystagmus, a PAX6 mutation may well be expected, but if none of these other ocular features are present then a PAX6 mutation may not be expected. However, these associated features should be looked for to define the CCO precisely.

\section{Axenfeld-Rieger anomaly/syndrome (ARA/S)}

Mutations in PITX2 and FOX C1 have been described to cause Axenfeld-Rieger anomaly/syndrome (ARA/S).
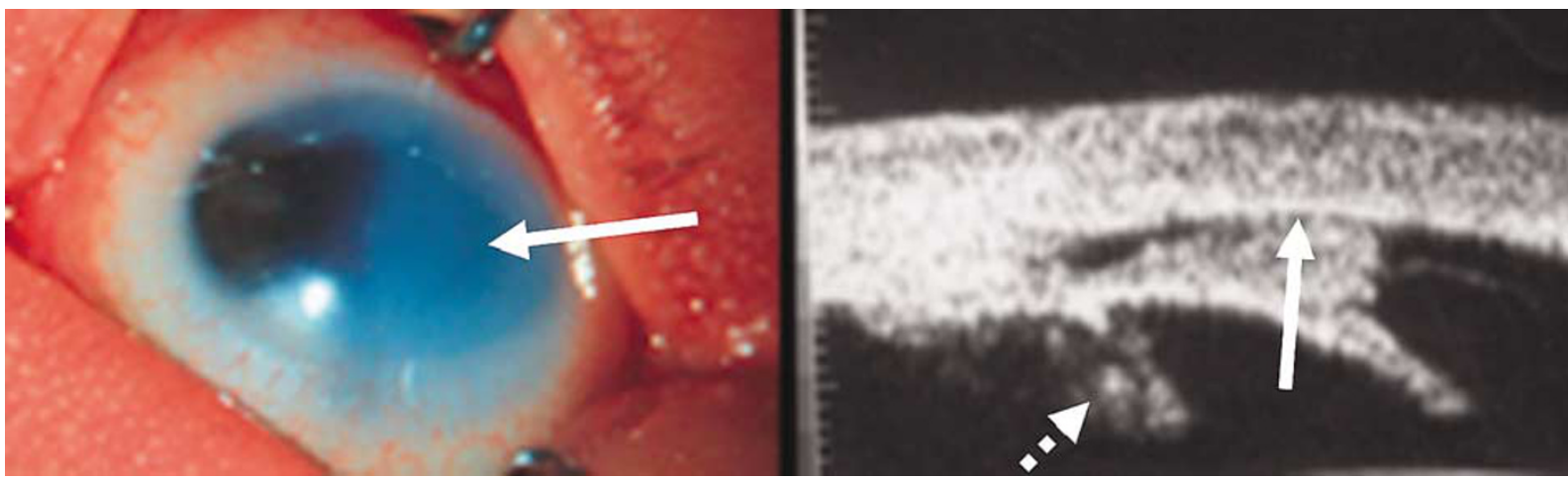

Figure $13 \mathrm{CCO}$ due to iridocorneal adhesion but no iris structural abnormality. Compare this figure to Figure 9; here there is iridocorneal adhesion but no disruption of the iris stroma. The corneal opacity appears to be due to a physical touch. The CCO shows no vascularization. 


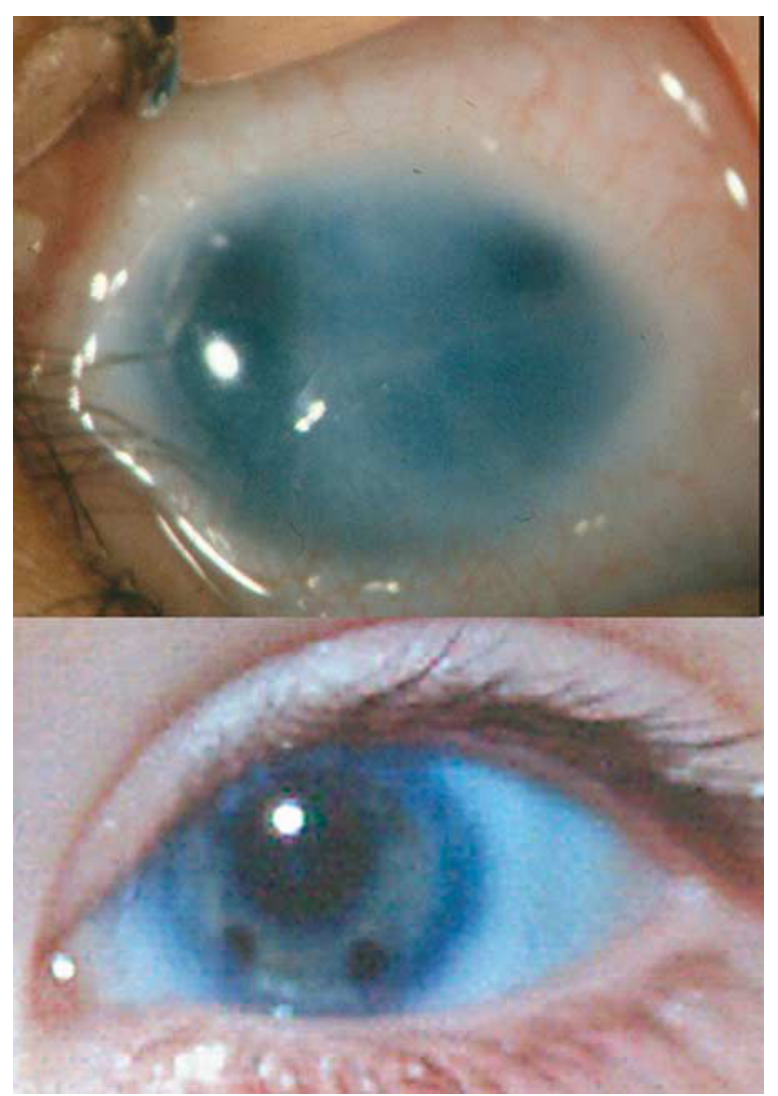

Figure 14 This child had bilateral CCO that were due to iridocorneal adhesions with no iris structural anomaly. PKP was performed at 6 weeks of age and 7 years later the corneal graft remains clear.

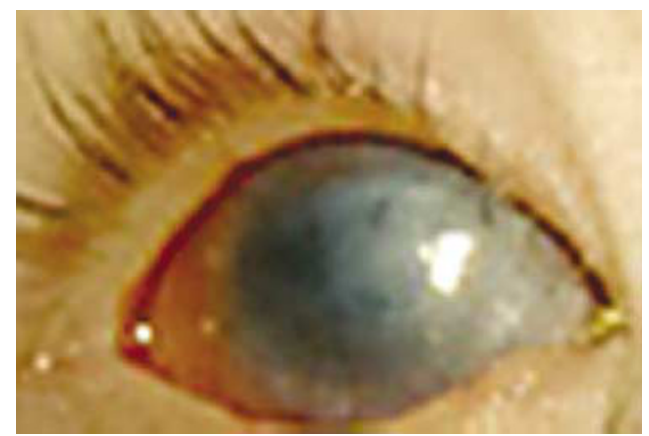

Figure 15 A case of primary aphakia diagnosed by HFU and at operation for PKP.

Mutations in PITX2 and FOXC1 have also been described in cases of Peters' anomaly. ${ }^{40,41}$ We have previously described a case of unilateral CCO where the 'good' eye had clear evidence of ARA and the affected eye had evidence of Axenfeld anomaly on HFU. ${ }^{3}$ Again the poor prognosticators in such cases are uncontrolled glaucoma.

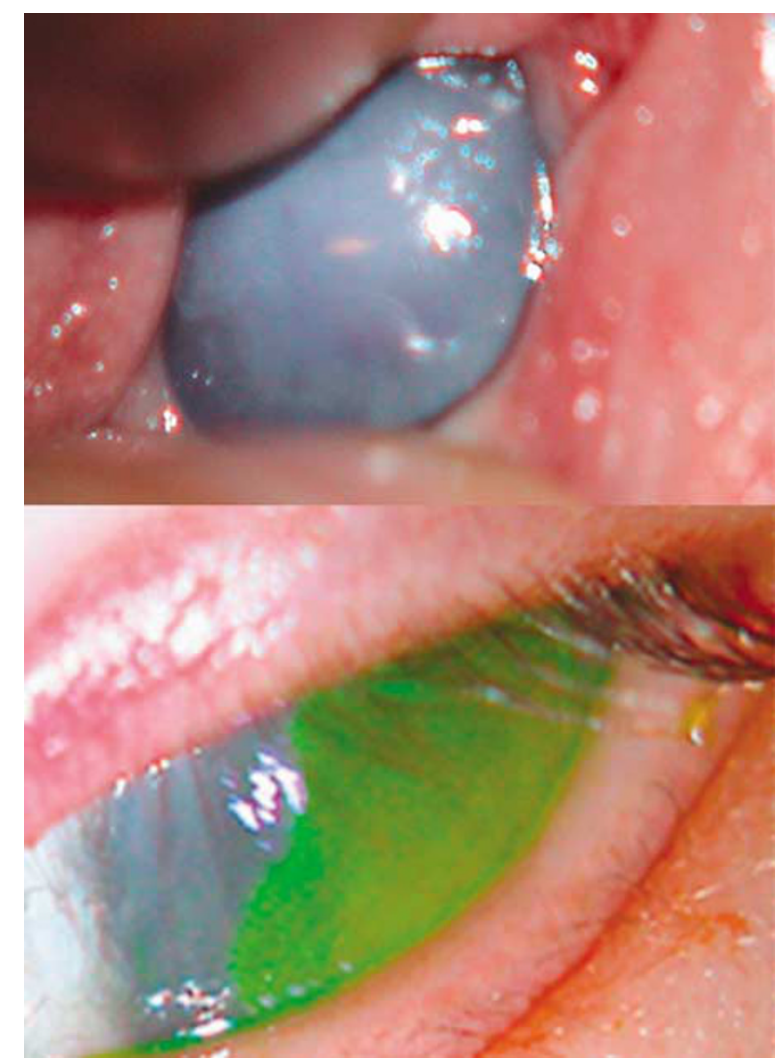

Figure 16 A case of neonatal Herpes simplex keratitis at presentation (above) and after 3 days of topical and systemic acyclovir (below).

Corneal ectasia (Figure 17) is likely to be a condition where there has been such an intraocular disruption with concomitant intrauterine glaucoma resulting in a grossly enlarged cornea with a stretched limbus. The presence of vascularization as shown in Figure 17, is again evidence in my experience of a noncorneal effect or event that has lead to an insult to the cornea or corneal development.

\section{Whole globe abnormalities}

These would be cases of complex microphthalmos (Figure 5), where the $\mathrm{CCO}$ is secondary to a general maldevelopment of the eye itself. Chromosomal anomalies are more likely in this group and in those cases with other organ or system anomalies.

\section{Developmental anomalies of the adnexa}

The best example of this is in clefting syndromes where the cleft involves the globe and results in a secondary CCO usually with disruption of the anterior segment (Figure 18). These cases are often beyond any surgical intervention for visual rehabilitation. 


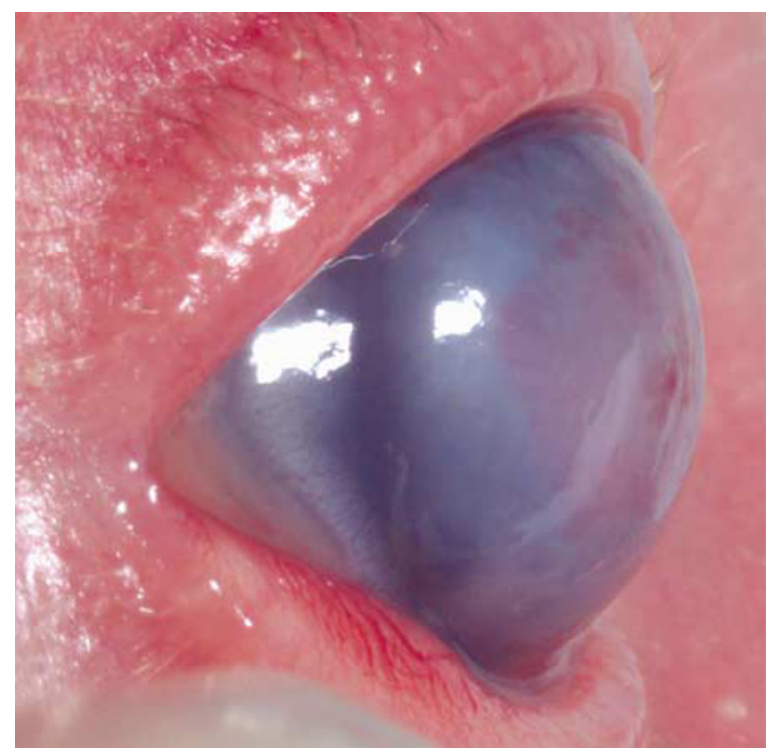

Figure 17 Corneal ectasia.

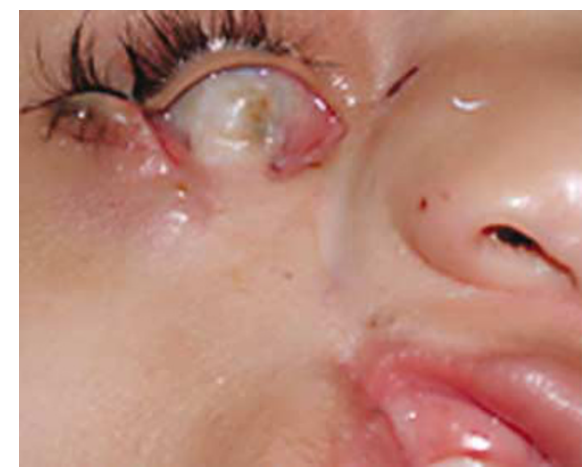

Figure 18 A case of clefting syndrome involving the palate, lip, and floor of the orbit. Note the complete disruption of the anterior segment of the eye.

\section{Summary}

There have been many studies describing the outcomes of surgical intervention (namely PKP) for Peters' anomaly/sclerocornea. It seems that we are unclear by using these terms, which have served us well for at least 100 years, about the phenotype that is being described. By moving to nomenclature, which describes primary and secondary CCO, we should be able to better configure genotype/phenotype correlation and in the meantime, better understand the prognosticators for infant PKP in cases of CCO.

In this author's opinion, defining the phenotype of CCO with either HFU, anterior segment OCT, or histology, should be mandatory before manuscripts of phenotype/genotype correlation or management outcome are accepted for publication. Only when this is done can we begin to unravel this extremely complex but fascinating subject.

\section{References}

1 Idrees F, Vaideanu D, Fraser SG, Sowden JC, Khaw PT. A review of anterior segment dysgeneses. Surv Ophthalmol 2006; 51(3): 213-231.

2 Peters A. Ueber angeborene Defektbildung der Descemetschen Membran. Klin Mbl Augenheilk 1906; 44: 27-40 and 105-119.

3 Nischal KK, Naor J, Jay V, MacKeen LD, Rootman DS. Clinicopathological correlation of congenital corneal opacification using ultrasound biomicroscopy. $\mathrm{Br} \mathrm{J}$ Ophthalmol 2002; 86(1): 62-69.

4 Mullaney PB, Risco JM, Teichmann K, Millar L. Congenital hereditary endothelial dystrophy associated with glaucoma. Ophthalmology 1995; 102(2): 186-192.

5 Threlkeld AB, Green WR, Quigley HA, de la Cruz Z, Stark WJ. A clinicopathologic study of posterior polymorphous dystrophy:implications for pathogenetic mechanism of the associated glaucoma. Trans Am Ophthalmol Soc 1994; 92: 133-165.

6 Kanis AB, Al-Rajhi AA, Taylor CM, Mathers WD, Folberg RY, Nishimura DY et al. Exclusion of AR-CHED from the chromosome 20 region containing the PPMD and AD-CHED loci. Ophthalmic Genet 1999; 20(4): 243-249.

7 Gwilliam R, Liskova P, Filipec M, Kmoch S, Jirsova K, Huckle EJ et al. Posterior polymorphous corneal dystrophy in Czech families maps to chromosome 20 and excludes the VSX1 gene. Invest Ophthalmol Vis Sci 2005; 46(12): 4480-4484.

8 Jiao X, Sultana A, Garg P, Ramamurthy B, Vemuganti GK, Gangopadhyay $\mathrm{N}$ et al. Autosomal recessive corneal endothelial dystrophy (CHED2) is associated with mutations in SLC4A11. J Med Genet 2007; 44(1): 64-68.

9 Wilson ME. Congenital iris ectropion and a new classification for anterior segment dysgenesis. J Pediatr Ophthalmol Strabismus 1990; 27(1): 48-55.

10 Michaeli A, Markovich A, Rootman DS. Corneal transplants for the treatment of congenital corneal opacities. J Pediatr Ophthalmol Strabismus 2005; 42(1): 34-44.

11 Tasse C, Majewski F, Bohringer S, Fischer S, Ludecke HJ, Gillessen-Kaesbach $\mathrm{G}$ et al. A family with autosomal dominant oculo-auriculo-vertebral spectrum. Clin Dysmorphol 2007; 16(1): 1-7.

12 Golubovic S, Latkovic Z, Horvatic-Obradovic M. Surgical treatment of large corneal dermoid. Doc Ophthalmol 1995; 91(1): 25-32.

13 Burillon C, Durand L. Solid dermoids of the limbus and the cornea. Ophthalmologica 1997; 211(6): 367-372.

14 Petroutsos G, Patey A, Savoldelli M, Pouliquen Y Sclerocornea and Ultrastructural and morphologic study. J Fr Ophtalmol 1983; 6(10): 769-775.

15 Waizenegger UR, Kohnen T, Weidle EG, Schutte E. Congenital familial cornea plana with ptosis, peripheral sclerocornea and conjunctival xerosis. Klin Monatsbl Augenheilkd 1995; 207(2): 111-116.

16 Fukuchi T, Ueda J, Hara H, Oota A, Watanabe J, Shirakashi $\mathrm{M}$, Abe $\mathrm{H}$ et al. Glaucoma with microcornea; morphometry and differential diagnosis. Nippon Ganka Gakkai Zasshi 1998; 102(11): 746-751. 
17 Sanyal S, Hawkins RK. Dysgenetic lens (dyl) - a new gene in the mouse. Invest Ophthalmol Vis Sci 1979; 18(60): 642-645.

18 Blixt $\AA$, Mahlapuu M, Aitola M, Pelto-Huikko M, Enerbäck $\mathrm{S}$, Carlsson P. A forkhead gene, FoxE3, is essential for lens epithelial proliferation and closure of the lens vesicle. Genes Dev 2000; 14: 245-254.

19 Ormestad M, Blixt A, Churchill A, Martinsson T, Enerback S, Carlsson P. haploinsufficiency in mice: a model for Peters anomaly. Invest Ophthalmol Vis Sci 2002; 43(5): 1350-1357.

20 Grimes PA, Koeberlein B, Favor J, Neuhauser-Klaus A, Stambolian D. Abnormal eye development associated with Cat4a, a dominant mouse cataract mutation on chromosome 8. Invest Ophthalmol Vis Sci 1998; 39(10): 1863-1869.

21 Cook CS, Sulik KK. Keratolenticular dysgenesis (Peters' anomaly) as a result of acute embryonic insult during gastrulation. J Pediatr Ophthalmol Strabismus 1988; 25(2): 60-66.

22 Townsend $\mathrm{W}$. Congenital anomalies of the cornea. In: Kaufman HE, Barron BA, McDonald MB (Eds) The Cornea. Second Edn. Butterworth-Heinemann, Boston, 37373-37376.

23 Duke-Elder S. System of Ophthalmology Vol. III. Normal and Abnormal Development Part I, Embryology. CV Mosby, St Louis, 1963.

24 Genis-Galvez JM. Role of the lens in the morphogenesis of the iris and cornea. Nature 1966; 210: 209-210.

25 Zinn KM. Changes in corneal ultrastructure resulting from early lens removal in the developing chick embryo. Invest Ophthalmol 1970; 9: 165-182.

26 Semina EV, Ferrell RE, Mintz-Hittner HA, Bitoun P, Alward $\mathrm{WL}$, Reiter RS et al. A novel homeobox gene PITX3 is mutated in families with autosomal-dominant cataracts and ASMD. Nat Genet 1998; 19: 167-170.

27 Semina EV, Murray JC, Reiter R, Hrstka RF, Graw J. Deletion in the promoter region and altered expression of Pitx3 homeobox gene in aphakia mice. Hum Mol Genet 2000; 9 : 1575-1585.

28 Valleix S, Niel F, Nedelec B, Algros MP, Schwartz C, Delbosc $\mathrm{B}$ et al. Homozygous nonsense mutation in the FOXE3 gene as a cause of congenital primary aphakia in humans. Am J Hum Genet 2006; 79(2): 358-364.

29 Johnson BL, Cheng KP. Congenital aphakia: clinicopathologic report of three cases. J Pediatr Ophthalmol Strabismus 1997; 34: 35-39.
30 Matsubara A, Ozeki H, Matsunaga N, Nozaki M, Ashikari $\mathrm{M}$, Shirai $\mathrm{S}$ et al. Histopathological examination of two cases of anterior staphyloma associated with Peters' anomaly and persistent hyperplastic primary vitreous. $\mathrm{Br} J$ Ophthalmol 2001; 85(12): 1421-1425.

31 McGannon P, Miyazaki Y, Gupta PC, Traboulsi EI, Colmenares C. Ocular abnormalities in mice lacking the Ski proto-oncogene. Invest Ophthalmol Vis Sci 2006; 47(10): 4231-4237.

32 Gallardo MJ, Johnson DA, Gaviria J, Nguyen L, Melendez R, Connor DA et al. Isolated herpes simplex keratoconjunctivitis in a neonate born by cesarean delivery. J AAPOS 2005; 9(3): 285-287.

33 Merin S, Beyth Y. Uniocular congenital blindness as a complication of midtrimester amniocentesis. Am J Ophthalmol 1980; 89(2): 299-301.

34 Sarfarazi M, Stoilov I. Molecular genetics of primary congenital glaucoma. Eye 2000; 14: 422-428.

35 Churchill AJ, Yeung A. A compound heterozygous change found in Peters' anomaly. Mol Vis 2005; 11: 66-70.

36 Vincent A, Billingsley G, Priston M, Glaser T, Oliver E, Walter $\mathrm{M}$ et al. Further support of the role of CYP1B1 in patients with Peters anomaly. Mol Vis 2006; 12: 506-510.

37 Hanson IM, Fletcher JM, Jordan T, Brown A, Taylor D, Adams RJ et al. Mutations at the PAX6 locus are found in heterogeneous anterior segment malformations including Peters' anomaly. Nat Genet 1994; 6(2): 168-173.

38 Beauchamp GR. Anterior segment dysgenesis keratolenticular adhesion and aniridia. J Pediatr Ophthalmol Strabismus 1980; 17(1): 55-58.

39 Churchill AJ, Booth AP, Anwar R, Markham AF. PAX 6 is normal in most cases of Peters' anomaly. Eye 1998; 12: 299-303.

40 Doward W, Perveen R, Lloyd IC, Ridgway AE, Wilson L, Black GC. A mutation in the RIEG1 gene associated with Peters' anomaly. J Med Genet 1999; 36(2): 152-155.

41 Honkanen RA, Nishimura DY, Swiderski RE, Bennett SR, Hong S, Kwon YH et al. A family with Axenfeld-Rieger syndrome and Peters anomaly caused by a point mutation (Phe112Ser) in the FOXC1 gene. Am J Ophthalmol 2003; 135(3): 368-375. 